\title{
Heterogeneous Popularity and Exporting Uncertainty
}

\author{
Eddy Bekkers
}

Published online: 18 May 2010

(C) The Author(s) 2010. This article is published with open access at Springerlink.com

\begin{abstract}
Empirical work shows that a considerable fraction of firms quit the export market soon after entrance. A natural interpretation to this quick exit from the export market is that firms did not predict the profitability of their variety correctly before entry. In this paper a firm heterogeneity model is put forward to account for this type of exporting uncertainty due to lack of information. Firms are heterogeneous with respect to the popularity of their good, technically the CES weight, and the popularity of a good varies across markets. Therefore, firms are uncertain about the profitability of their good in the export market. Upon payment of sunk export costs the popularity of the good is revealed and some firms stay in the export market while others leave. Comparative statics show that lower sunk export costs lead to higher probability that firms start to export, but to lower probability of export success. Lower fixed export costs instead lead to both a higher probability to start exporting and to be successful in exporting.
\end{abstract}

Keywords Firm heterogeneity • Exporting uncertainty

JEL Classification F12

Thanks are due to participants in seminars at Erasmus University Rotterdam and the University of Linz, to Joseph Francois and to anonymous referees for various valuable comments.

\section{E. Bekkers $(\varangle)$}

Department of Economics, Johannes Kepler University of Linz,

Altenbergerstrasse 69, $4040 \mathrm{Linz}$, Austria

e-mail: eddybekkers@gmail.com 


\section{Introduction}

Empirical work shows that a significant fraction of firms quit the export market soon after entrance. Bernard and Jensen (2004) report that $15 \%$ of the exporting firms leave the export market every year in a sample of American firms between 1984 and 1992. Almost 5\% of the firms have left the export market already the year after entry and do not return again on the export market afterwards (calculations from Table 5 of Bernard and Jensen 2004). Irarrazabal and Opromolla (2006) find that 16\% of the exporting firms leave the export market every year in a sample of Chilean firms between 1990 and 1996. They do not calculate which fraction of quitters from the export market had just entered the export market. Other evidence on quick exit can be found in Eaton et al. (2007). They show in a panel of Colombian firms between 1996 and 2005 where each single export transaction is recorded that 'the survival rate among first-year exporters is typically around one-third, and in some cases is much lower (Eaton et al. 2007, p. 19).' Hence two-third of the starting exporters drop out within a year. Indirect evidence on the quick exit of firms from the export market after entry comes from duration analysis on detailed export categories. Besedes and Prusa (2006) show with a US dataset between 1992 and 2001 of detailed product categories that around one third of imports (depending on the data) in a product category for differentiated products stop again within 1 year. Nitsch (2007) finds in a sample of German imports between 1995 and 2005 that $40 \%$ of the newly emerging import product categories stop within 1 year. ${ }^{1}$

So, empirical evidence shows that there is a lot of exit from the export market shortly after entry. Broadly, two reasons for exit from the export market can be identified. On the one hand, variables affecting profitability in the export market display variation. Negative shocks to such variables can induce firms to drop out of the export market. Baldwin (1988) and Baldwin and Krugman (1989) for example model fluctuations in exchange rates. Their model shows that sunk export costs lead to persistent trade effects of exchange rate shocks. Irarrazabal and Opromolla (2006) make productivity a stochastic process in a Melitz-type model of trade to explain that firms can leave the export market again after entrance.

On the other hand, firm exit from the export market can be due to the fact that firms simply do not have (enough) information about profitability in the export market. The model presented in this paper follows this view. Firms cannot assess the popularity of their good in the export market before they enter the export market. After entrance, the popularity of their good could be too low to produce profitably. An example of this type of exporting uncertainty

\footnotetext{
${ }^{1}$ These studies correct for censoring as a result of redefining product categories. As these data are on product categories, the hazard rates are a lower bound for the hazard rates for individual firms given that more firms could trade in one product category. On the other hand continuing exports of a certain variety could be recorded as exit from a product category when firms switch product categories with their variety.
} 
is the withdrawal of Wal-Mart from the German and South-Korean export market. After a presence of some years on these foreign markets incurring huge losses, Wal-Mart gathered enough information to realize that their 'product-type' was not popular enough in these foreign markets. Nguyen (2008) also follows an approach where firms drop out of the export market after they get to know their profitability on the export market. The difference is that in our model firms get to know their profitability by incurring sunk entry costs, whereas in Nguyen (2008) firms get information about their profitability by selling in the foreign market. Below there is a comparison of the approach in Nguyen (2008) and in the current paper.

The model in this paper is a firm heterogeneity model (in the spirit of Melitz 2003) taking into account exporting uncertainty. There is heterogeneity in the taste parameter (the CES-weight) of a variety instead of in productivity and the taste parameters of the same variety are different in the domestic and exporting market. Firms are uncertain about the popularity of their good, reflected in the taste parameter, before they start producing ánd before they start exporting. Sunk costs have to be paid to learn the popularity of the good both in the domestic and exporting market. The economic literature provides ample evidence for the existence of sunk export costs (See for example Baldwin and Krugman 1989; Roberts and Tybout 1997; Das et al. 2007; Albarran et al. 2009). In a survey study of exporting firms in the UK, (Kneller and Pisu 2008) find that firms report market exploration costs as an important barrier to trade. In particular, $26 \%$ of the firms that started exporting mention 'obtaining basic information about an export market' and $41 \%$ mention 'the marketing costs of doing business in an overseas market' as a barrier to trade. Hence, sunk export costs consist (partly) of market research costs.

Differences in taste parameters have a more natural interpretation than differences in productivity: preferences are different across countries. It is assumed that the taste parameters on the different markets correlate, albeit imperfectly. The correlation between taste parameters is a function of the cultural proximity between countries. Felbermayr and Toubal (2010) show in empirical work that a higher level of cultural proximity leads to higher levels of trade through a larger similarity of preferences. ${ }^{2}$

The model's solution contains an additional endogenous variable, the cutoff taste parameter below which a firm does not consider exporting. A firm with a taste parameter above this cutoff value starts exporting but can be unsuccessful when its product is not popular enough on the foreign market. This drives the exporting uncertainty. The model generates three cutoff taste parameters, a domestic cutoff taste parameter, a cutoff taste parameter to start exporting and a cutoff taste parameter to be successful in exporting.

\footnotetext{
${ }^{2}$ As discussed in Section 3, we can generalize the setup and make firms heterogeneous in both taste parameter and productivity. This implies that the sunk entry costs would also consist partly of costs to find out the costs of production abroad.
} 
The effects of changes in the different types of trade costs display interesting patterns. The effect of lower iceberg trade costs is as expected: the domestic cutoff value increases, whereas both exporting cutoff levels decrease. But the effects of lower sunk export costs and of lower fixed export costs are different on the two exporting cutoff values. Lower sunk export costs decrease the cutoff level to start exporting and raise the cutoff level for successful exporting, whereas lower fixed export costs decrease the cutoff level to start exporting and the cutoff level for successful exporting. The implication is that both lower sunk and fixed export costs lead to a higher probability that a firm will start exporting. But lower sunk export costs decrease the probability of success in the export market, whereas lower fixed export costs raise the probability of successful entry into the export market. The different effect of changes in sunk and fixed export costs on the success rate of exporting can be explained as follows: lower sunk export costs do not affect operational profits from exporting. Therefore, they raise the cutoff level to be successful in exporting to restore the ex ante free entry condition. Still, because of the lower sunk export costs it becomes attractive for more firms to try to start exporting. The result is that more firms start exporting, but the hurdle to be successful is higher. Therefore, the success rate declines. With lower fixed export costs instead the operational profits from exporting rise. Therefore, the cutoff level to be profitable in exporting declines. The cutoff level to start exporting also declines, but the effect on cutoff level for successful exporting is so large that of the larger number of firms that start exporting also more firms will be successful.

The different types of trade costs are a function of different types of trade barriers. Therefore, the derived comparative statics have implications for the effect of changing various types of trade barriers. Iceberg trade costs are a function of tariffs and per unit nontariff barriers. Fixed export costs are related to the regulatory burden of trade that appear each period like the costs of complying with customs procedures, acquiring licenses to import. Sunk export costs are a function of the regulatory burden of trade facing an exporter when starting to export, like collecting information on import procedures.

The welfare effects of lower trade costs are for all three types of trade costs positive. This is remarkable for a decrease in sunk export costs, as they make entrance into the export market more probable, whereas success in the export market becomes less likely. Hence, more resources are dissipated in the entry process. The welfare effect is still positive, because in a Melitz type of model a higher demand for resources, also if used 'non-productively,' is the driving force for a welfare increase. It bids up real wages and squeezes thereby the least productive firms out of the market leading to higher average welfare. The policy conclusion is that programs to stimulate entrepreneurs to focus on foreign markets by helping them in dealing with regulations, procedures and information problems when starting to export do have positive welfare effects. And the welfare effects are also positive if a large fraction of the firms that start exporting do not succeed. 
This paper contributes to the literature on models with both exporting uncertainty and firm heterogeneity. Crozet et al. (2007) model uncertainty about the political environment to explain that less productive firms who were 'lucky' not to face bribes can enter a market whereas certain more productive firms cannot. In the already mentioned work of Irarrazabal and Opromolla (2006) firms' productivities are a stochastic process. Some exporting firms will have to leave the exporting market because their productivity experienced a negative shock. Finally, there is structural estimation empirical work proving the importance of sunk export costs where firms are heterogeneous and face shocks to various variables (see for example Roberts and Tybout 1997; Das et al. 2007).

The paper differentiates itself from these other models by starting from the view that uncertainty is due to a lack of information on exporting profitability. There is ample empirical evidence that both sources of uncertainty, lack of information on, and shocks to, variables affecting profitability are important. Firm level data show that a considerable fraction of exit from the export market is shortly after entry, although estimates differ across studies. Also, not only firms that leave the export market immediately after entrance are support for the approach in this paper. Firms can stay in the market for some years before they know whether their product is popular enough and whether they can be profitable (firms could incur losses in a foreign market for some years until they are convinced they cannot be profitably like the Wal-Mart example mentioned). Moreover, data on duration of detailed export categories show that a large fraction of export flows become zero quickly after entry.

This paper is also related to the literature on the role of networks in trade. Rauch and Watson (2003) propose a model where buyers are involved in costly search for potential importers. After being matched with an importer they get to know the cost of the importer. They can either buy a small amount from the importer generating zero surplus or invest a lump-sum amount to get to know whether the importer can process a large order. If the answer is yes a larger surplus from trade can be generated. The model by Rauch and Watson (2003) can also explain a large fraction of exiting firms from the export market soon after entry. The model proposed below is similar. An important difference is that in the model below sellers take the initiative to try and sell a product profitably, whereas in Rauch and Watson (2003) buyers approach possible importers. Another difference is that in the model below, exports will be larger to countries that are culturally closer having more similar preferences, whereas in Rauch and Watson (2003) exports to countries with closer business ties and denser networks will be larger. ${ }^{3}$

\footnotetext{
${ }^{3}$ Guiso et al. (2004) fits into the view put forward by Rauch and Watson (2003). They show that cultural proximity increases the amount of trade between two countries through an increase in levels of trust between people of the two countries. Unfortunately, they do not address the possible effect of cultural proximity through similarity of tastes.
} 
Rauch (1999) dismisses a type of model similar to the one in the present paper where producers produce varieties that are most popular in the home market and their popularity in other markets declines with (cultural) distance. He puts forward two pieces of evidence. First, he shows that a dummy for colonial ties between countries raises trade whereas a dummy for common language has hardly a significant effect. In his reading colonial ties proxy business ties whereas a common language proxies similar tastes. This implies that the empirical evidence supports the network view in his work and dismisses the tastes view in the present paper. But it is disputable whether business ties are exclusively proxied by colonial ties whereas similar tastes are exclusively proxied by common language. A common language also eases business ties and colonial ties are likely to lead to more similar tastes as well as to more intense business ties.

Second, he refers to a study by Gould (1994) who finds that immigration into the USA raises bilateral trade with the country of origin of the immigrants. The effect is stronger on exports from the USA than on imports, however, favoring a network view over a shared tastes view. But this evidence does not prove that the shared tastes view is not important. Indeed (Felbermayr and Toubal 2010) use empirical evidence to show that cultural proximity of countries raises trade both because this leads to lower trade costs (implying closer business ties emphasized by Rauch 1999) and because it implies more similar tastes. Hence, both channels seem to be important.

The work by Nguyen (2008) is similar to the current paper. Nguyen (2008) also proposes a model of firm heterogeneity in popularity with different although correlated popularity across markets. The main difference with the current paper is that in Nguyen (2008) firms learn their popularity in a market by selling one period, whereas in the current paper firms get to know their popularity by incurring sunk entry costs. Two distinct empirical literatures are useful in comparing these two approaches. First, the international management literature on strategies to enter export markets provides support for both approaches. As discussed by Dana (2006) the early literature on exporting strategies stresses the gradual approach to exporting, also dubbed the Uppsala process model. Firms gradually commit more resources to the export market as they acquire experiential knowledge being active in foreign markets. This model of foreign market entry fits into the theory of Nguyen (2008). But some papers cast doubt about the gradual approach and argue that firms move quickly into export markets leapfrogging stages of internationalization by investing large sums of money at the initial stage of entry into the export market, see for example (Hedlund and Kverneland 1985; Millington and Bayliss 1990).

Second, several papers provide strong evidence for the existence of sunk costs of exporting, for example (Baldwin and Krugman 1989; Roberts and Tybout 1997; Das et al. 2007). In particular, these papers show that firms exporting in the previous year are much more likely to export the current year, holding constant other factors. This implies that new entrants have lower expected profits than incumbents, because they have to incur sunk costs in 
their first year of exporting. This empirical finding is difficult to reconcile with a model of learning through exporting without sunk costs like (Nguyen 2008). If firms have correct priors before starting to export, the probability to be in the export market will be independent of export presence in the previous year.

Like Nguyen (2008) also Eaton et al. (2008) and Albornoz et al. (2010) propose a model of learning through exporting to provide an explanation for (among others) the fact that a large fraction of exporting firms leaves the exporting market shortly after entry. But the focus of these papers is more on the growth dynamics of exporters after entry.

The next section points out preferences, demand, revenues and profits and solves the closed economy model. Section 3 solves the open economy model. Section 4 outlines the effects of changes in different types of trade costs. Section 5 contains some concluding remarks.

\section{Closed economy}

Assume that all goods in the economy belong to the differentiated goods sector. There is a mass of consumers $L$ with an equal CES utility function with CES weights or taste parameters $\alpha_{v}$ that differ across varieties $v$ :

$$
U=\left[\int_{v \in V} \alpha_{v}^{\frac{1}{\sigma}} c_{v}^{\frac{\sigma-1}{\sigma}} d v\right]^{\frac{\sigma}{\sigma-1}}
$$

Raising the CES weight $\alpha_{v}$ to the power $1 / \sigma$ is an innocuous assumption. It will turn out to be computationally convenient later on. There is only one factor of production, labor, and the wage is normalized at 1 . Therefore, the demand facing a firm is given by:

$$
x_{v}=L c_{v}=\alpha_{v} p_{v}^{-\sigma} P^{\sigma-1} L
$$

$P$ is the price index defined by:

$$
P=\left[\int_{v \in V} \alpha_{v} p_{v}^{1-\sigma} d v\right]^{\frac{1}{1-\sigma}}
$$

Production is increasing returns with a fixed cost of production. There is one factor of production, labor. Wages are normalized at 1 and it is assumed that productivity is homogeneous. ${ }^{4}$ The cost function depends upon marginal costs $a$ and fixed costs $f$ and is given by:

$$
C\left(x_{v}\right)=a x_{v}+f
$$

\footnotetext{
${ }^{4}$ This can be generalized, making marginal costs dependent on the CES-weight, like in Baldwin and Harrigan (2007). But such a generalization would not add anything to the analysis and would not change the main results. Therefore, for computational simplicity the marginal cost is kept equal across firms.
} 
A firm can only start to produce when it has incurred sunk entry costs $f_{e}$. Paying these sunk costs reveals a firm's taste parameter $\alpha_{v}$. This seems a more natural interpretation of the sunk entry costs than in Melitz (2003). Firms have to explore the desirability of their product in the market and this requires sunken investments.

The pricing equation of a firm is independent from the taste parameter:

$$
p_{v}=\frac{\sigma}{\sigma-1} a
$$

Revenues and profits of a firm do depend on the taste parameter:

$$
\begin{gathered}
r\left(\alpha_{v}\right)=p_{v} x_{v}=\alpha_{v} p_{v}^{1-\sigma} P^{\sigma-1} L=\alpha_{v}\left(\frac{\sigma}{\sigma-1} a\right)^{1-\sigma} P^{\sigma-1} L \\
\pi\left(\alpha_{v}\right)=\frac{r\left(\alpha_{v}\right)}{\sigma}-f
\end{gathered}
$$

Immediately after entry firms decide whether to stay in business or not. When they can make positive profit they stay, otherwise they exit immediately. The taste parameter value at which they are just indifferent about producing is the cutoff taste parameter $\alpha^{*}$. Producing firms have a fixed death probability $\delta$ each period. Entrants draw from an initial distribution of taste parameters $G(\alpha)$. The truncated distribution of taste parameters of producing firms follows from this initial distribution: ${ }^{5}$

$$
\mu(\alpha)=\frac{1}{1-G\left(\alpha^{*}\right)} g(\alpha)
$$

With this expression the average taste parameter from Eq. (10) can be expressed as a function of the cutoff taste parameter:

$$
\widetilde{\alpha}\left(\alpha^{*}\right)=\frac{1}{1-G\left(\alpha^{*}\right)} \int_{\alpha^{*}}^{\infty} \alpha g(\alpha) d \alpha
$$

The price index can be expressed as a function of the average taste parameter $\alpha$ and the mass of firms $N$ :

$$
P=\left[\int_{\alpha^{*}}^{\infty} p^{1-\sigma} \alpha N \mu(\alpha) d \alpha\right]^{\frac{1}{1-\sigma}}=p N^{\frac{1}{1-\sigma}} \widetilde{a}^{\frac{1}{1-\sigma}}
$$

$\tilde{a}$ is the average taste parameter and defined as:

$$
\widetilde{a}=\int_{\alpha^{*}}^{\infty} \alpha \mu(\alpha) d \alpha
$$

$\mu(\alpha)$ is the distribution density of taste parameters of producing firms. Note that variables with $\mathrm{a} \sim$ are averages conditional upon successful entry.

\footnotetext{
${ }^{5}$ As Melitz (2003) points out in footnote 13, the equilibrium truncated distribution follows from the distribution of initial productivities applying the law of large numbers.
} 
In equilibrium a zero cutoff profit condition (ZCP) and a free entry condition (FE) have to be satisfied, like in Melitz (2003). The ZCP is given by:

$$
\pi\left(\alpha^{*}\right)=0
$$

The ZCP can be rewritten as a function of average profit and the cutoff taste parameter:

$$
\left.\begin{array}{c}
r\left(\alpha^{*}\right)=\sigma f \\
r\left(\alpha^{*}\right)=\frac{\alpha^{*}}{\widetilde{\alpha}} \\
r(\widetilde{\alpha})=\sigma(\pi(\tilde{\widetilde{\alpha}})+f)
\end{array}\right\} \tilde{\pi}=\pi(\widetilde{\alpha})=f\left[\frac{\widetilde{\alpha}}{\alpha^{*}}-1\right]
$$

Note that profit and revenue of the firm with average taste parameter are equal to average profit and average revenue. The FE is given by:

$$
\tilde{\pi}=\frac{\delta f_{e}}{1-G\left(\alpha^{*}\right)}
$$

The equilibrium cutoff taste parameter is found by combining the ZCP, the FE and the definition for the average taste parameter, Eqs. (12), (13) and (8) respectively and the proof of existence of a unique equilibrium for $\alpha^{*}$ and $\tilde{\pi}$ from the ZCP and FE is fully analogous to Melitz (2003).

There is a stationary equilibrium with the mass of entering firms equal to the mass of dying firms. ${ }^{6}$ The mass of successful entrants in each period is equal to $\left(1-G\left(\alpha^{*}\right)\right) N_{e}$, with $N_{e}$ the mass of (successful and unsuccessful) entrants. The mass of dying firms is equal to $\delta N$ with $N$ the number of firms producing. In stationary equilibrium, $\left(1-G\left(\alpha^{*}\right)\right) N_{e}=\delta N$. Labor can be used in production, indicated by $L_{p}$, or in the development of new varieties, indicated by $L_{e}$. Using the stationary equilibrium condition and the free entry condition, implies the following expression for $L_{e}$ :

$$
L_{e}=N_{e} f_{e}=\frac{\delta N f_{e}}{1-G\left(\alpha^{*}\right)}=N \tilde{\pi}
$$

The payments to labor in production, $L_{p}$, are equal to aggregate revenues minus aggregate profits, $L_{p}=N \widetilde{r}-N \tilde{\pi}$. Hence, adding $L_{p}$ and $L_{e}$ implies that aggregate revenues are equal to the size of the labor force, $L=L_{p}+L_{e}=N$ $\widetilde{r}$. The mass of firms $N$ can be solved from the solution for average profit following from the ZCP and FE, Eqs. (12) and (13), using $N=L /(\tilde{\pi}+\sigma f)$.

\section{Open economy model}

To model the open economy, uncertainty in the exporting decision is included. To this end, the taste parameter abroad is assumed to be different from

\footnotetext{
${ }^{6}$ Working with a mass of firms implies a stationary equilibrium with all aggregate variables (price index, aggregate revenues) staying constant over time. With a discrete number of firms the equilibrium would wander around, see for discussion (Bekkers and Francois 2010).
} 
the taste parameter domestically. ${ }^{7}$ So, success on the domestic market is no guarantee for success on the foreign market. Empirically this is important as many firms leave the foreign market shortly after they entered it. The foreign taste parameter is assumed to be related to the domestic taste parameter in the following way:

$$
\alpha_{v}^{F}=\beta \alpha_{v}^{H}+\varepsilon_{v}
$$

$\varepsilon_{v}$ is a random variable with mean 0 and variance $\sigma_{\varepsilon}^{2} \cdot 0 \leq \beta \leq 1$. When $\sigma_{\varepsilon}=0$ uncertainty disappears. The superscripts $H$ and $F$ indicate home and foreign variables respectively. According to Eq. (14) popularity in the domestic market tells something about popularity on the foreign market, but not everything. The value of $\beta$ can be seen as a measure for 'psychic distance,' a concept from the marketing literature. Psychic distance is an indicator of for example differences in language, consumer behavior and cultural standards between markets (Stoettinger and Schlegelmilch 1998). Equivalently it can be seen as a measure for 'cultural proximity,' a similar concept as psychic distance applied in Felbermayr and Toubal (2010). These authors show that countries that are culturally more proximate trade more because trade costs are lower, but also because preferences are more similar.

The remaining assumptions on the open economy keep the economy as simple as possible. There are two countries, the distribution of taste parameters is equal in both countries and the size of the economy is equal to ensure equal wages. There are three types of export costs, iceberg trade costs $\tau$, fixed (per period) export costs $f_{x}$ and sunk export costs $f_{e x}$. The sunk export costs are paid when a firm starts exporting. The fixed export costs are paid each period by producing firms.

Without exporting uncertainty, like in Melitz (2003) for example, either the sunk export costs or the fixed export costs would be redundant. Each firm that enters the export market knows ex ante whether it can produce profitably. This implies that the sunk export costs could be expressed as the amortized per period equivalents. Instead, to model exporting uncertainty, one needs both sunk export costs and fixed export costs. Without sunk export costs, none of the firms that enters the export market would drop out of the export market. Firms would never have entered, because they know their profitability in the export market without paying any sunk cost. There also have to be fixed export costs $f_{x}$ in the model to be able to account for exporting uncertainty. With CES demand all firms face at least some demand for their variety. So, without fixed export costs, each firm that would start exporting would continue exporting.

The existence of sunk export costs is widely discussed in the literature (Baldwin 1988; Baldwin and Krugman 1989). Exporting is very persistent

\footnotetext{
${ }^{7}$ Also differences in productivity across markets could drive uncertainty about exporting profitability because part of a firm's costs are related to sales which will vary by destination market. In a more general setup as mentioned in footnote 2, firms could be heterogeneous in both popularity and productivity and the combined popularity and productivity could then also be different across markets. But this does not lead to additional insights.
} 


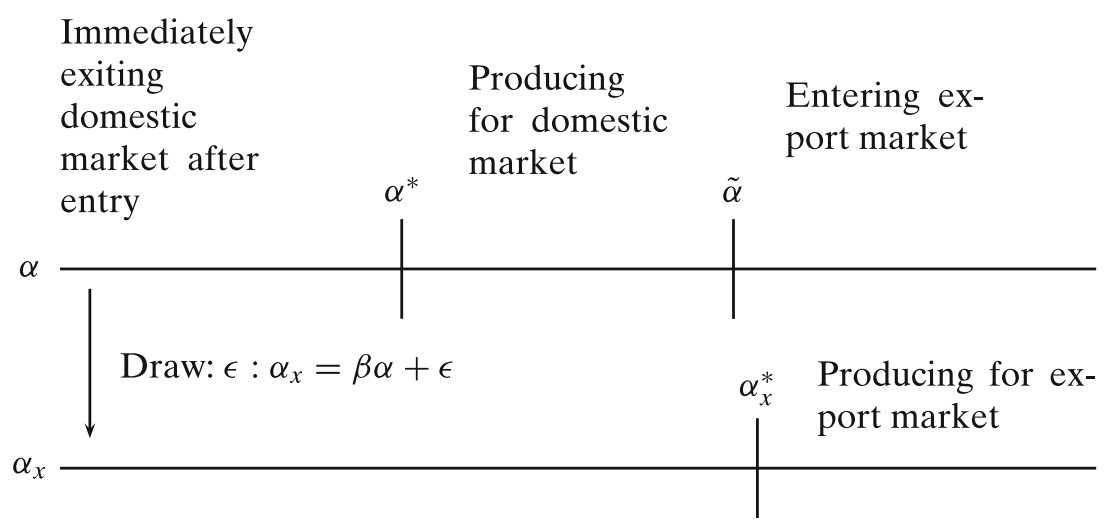

Fig. 1 The different categories of firms depending on their taste parameter

implying the existence of sunk export costs. Roberts and Tybout (1997) present empirical evidence on the existence of sunk export costs in a sample of Colombian industries. On the existence of fixed export costs there is less empirical work. Some other papers feature the presence of fixed exports costs in their trade model. In particular, Venables (1994), Jean (2002), Medin (2003) assume fixed export costs in their models.

To solve for the equilibrium of the model, three cutoff taste parameters have to be determined, the domestic cutoff taste parameter $\alpha^{*}$, the cutoff taste parameter that defines the firm that just starts exporting $\breve{\alpha}$, and the exporting cutoff taste parameter, $\alpha_{x}^{*}$, that determines the firm that just continues exporting. These three variables will be related as in Fig. 1.

There is a fraction of firms with a taste parameter below the domestic cutoff value, which immediately exit after they tried to enter the domestic market. There is a fraction of firms that produces only for the domestic market. There is a fraction of firms that enters the export market but leaves immediately, because its taste parameter is not large enough and finally there is a fraction of firms that produces both for the domestic and the exporting market. ${ }^{8}$ From Fig. 1 the differences with the models of Melitz (2003) and Nguyen (2008) become clear. In Melitz (2003) firms draw $\alpha$ (or productivity in that model), which is equal in the domestic and exporting market. Hence, there is no need to draw $\varepsilon$ to get to know the exporting popularity $\alpha_{x}$. Also, the parameter to enter the exporting market $\breve{\alpha}$ and to be successful in the export market $\alpha_{x}^{*}$ are equal. In Nguyen (2008) domestic and exporting popularity $\alpha$ and $\alpha_{x}$ are different like in the current paper, but in Nguyen (2008) firms get to know this productivity only by producing one period. Like in the current paper there is also a distinction between the cutoff level to start exporting and the cutoff

\footnotetext{
${ }^{8} \breve{\alpha}$ can both be larger or smaller than $\alpha_{x}^{*}$, depending on how stark domestic and exporting taste parameters are correlated, which is a function of the parameter $\beta$ in Eq. (14). This becomes clear formally below in the zero profit condition for exporting, Eq. (23).
} 
level for successful exporting. But in Nguyen (2008) producing in one of the markets reveals information about profitability in the other market, whereas in the current model an additional sunk cost for the exporting market has to be paid to find out profitability in the export market.

Solving the model requires finding the cutoff values. Given the cutoff values, one can determine the number of firms active in the different markets from the steady state equations and the labor market equilibrium equations. One starts from the domestic and exporting ZCP:

$$
\begin{aligned}
& \tilde{\pi}_{d}=f\left[\frac{\tilde{\alpha}}{\alpha^{*}}-1\right] \\
& \tilde{\pi}_{x}=f_{x}\left[\frac{\widetilde{\alpha}_{x}}{\alpha_{x}^{*}}-1\right]
\end{aligned}
$$

$\tilde{\pi}_{x}$ is average profit from exporting conditional upon successful entry in the exporting market. $f_{x}$ are the fixed costs in exporting. $\widetilde{\alpha}_{x}\left(\alpha_{x}^{*}, \breve{\alpha}\right)$ is the average exporting taste parameter, defined as:

$$
\widetilde{\alpha}_{x}\left(\alpha_{x}^{*}, \breve{\alpha}\right)=\frac{1}{1-H\left(\alpha_{x}^{*}, \breve{\alpha}\right)} \int_{\alpha_{x}^{*}}^{\infty} \alpha_{x} h\left(\alpha_{x}, \breve{\alpha}\right) d \alpha_{x}
$$

$h\left(\alpha_{x}, \breve{\alpha}\right)$ is the distribution of taste parameters in the exporting market $\alpha_{x}$ conditional upon entering the export market (and thus having a domestic taste parameter larger than $\breve{\alpha}$ ) and can be found from the density functions of $\alpha$, $g(\alpha)$ and $\varepsilon, t(\varepsilon)$ as follows: ${ }^{9}$

$$
h\left(\alpha_{x}, \breve{\alpha}\right)=\frac{1}{1-G(\breve{\alpha})} \int_{\beta \breve{\alpha}}^{\infty} \frac{1}{\beta} g\left(\frac{x}{\beta}\right) t\left(\alpha_{x}-x\right) d x
$$

Without fixed export costs, the cutoff taste parameter in exporting $\alpha_{x}^{*}$ would be equal to 0 . All firms that start exporting would also continue exporting (until they die according to the death probability $\delta$ ). So, without fixed exporting costs, there would be no exporting uncertainty.

Dividing the exporting ZCP by the domestic ZCP gives a relation between the exporting cutoff taste parameter and the domestic one:

$$
\alpha_{x}^{*}=\frac{f_{x}}{f} \tau^{\sigma-1} \alpha^{*}
$$

To continue solving the model, the average profits in the two $\mathrm{ZCP}$-conditions should be added to get an equation in average profit. The latter is the average profit conditional upon entry in the domestic market. This complicates

\footnotetext{
${ }^{9}$ Equation 18 can be derived as follows. $h\left(\alpha_{x}, \breve{\alpha}\right)$ is the density of $\alpha_{x}=\beta \alpha+\varepsilon$ conditional upon $\alpha$ larger than $\breve{\alpha}$. The truncated density of $\beta \alpha$ truncated at $\breve{\alpha}, f_{\beta \alpha}(x)$ is equal to $f_{\beta \alpha}(x)=\frac{\frac{1}{\beta} g\left(\frac{x}{\beta}\right)}{1-G(\breve{\alpha})}$. Using the rule for the density of a sum, $h\left(\alpha_{x}, \breve{\alpha}\right)$ will be as defined in Eq. (18).
} 
things as the domestic taste parameter is correlated with the exporting taste parameter. Average profit conditional upon domestic entry is given by:

$$
\tilde{\pi}=\tilde{\pi}_{d}+\operatorname{Pr}\left(\alpha \geq \breve{\alpha} \mid \alpha \geq \alpha^{*}\right)\left[\operatorname{Pr}\left(\alpha_{x} \geq \alpha_{x}^{*} \mid \alpha \geq \breve{\alpha}\right) \tilde{\pi}_{x}-\delta f_{e x}\right]
$$

So, (20) says that the average profit from exports conditional upon entry into the domestic market is equal to the probability a firm starts exporting, $\operatorname{Pr}\left(\alpha \geq \breve{\alpha} \mid \alpha \geq \alpha^{*}\right)$, times the expected profits of an exporting firm, $\operatorname{Pr}\left(\alpha_{x} \geq \alpha_{x}^{*} \mid \alpha \geq \alpha^{*}\right) \tilde{\pi}_{x}-\delta f_{\text {ex }}$. The conditional probability in the latter term is equal to $1-H\left(\alpha_{x}^{*}, \breve{\alpha}\right)$.

Combining (15), (16) and (20) one can express expected profit as a function of the domestic cutoff and the zero exporting profit taste parameters:

$$
\tilde{\pi}=f\left[\frac{\widetilde{\alpha}}{\alpha^{*}}-1\right]+\frac{1-G(\breve{\alpha})}{1-G\left(\alpha^{*}\right)}\left[\left(1-H\left(\alpha_{x}^{*}, \breve{\alpha}\right)\right) f_{x}\left[\frac{\widetilde{\alpha}_{x}}{\alpha_{x}^{*}}-1\right]-\delta f_{e x}\right]
$$

The free entry equation is like in the closed economy, as defined in Eq. (13). To find the equilibrium values a zero profit equation from exporting has to be added, i.e. the firm with domestic taste parameter that makes zero profit from exporting inclusive of sunk export costs should be defined. This firm's taste parameter $\breve{\alpha}$ is defined by the following zero expected profit condition:

$$
\operatorname{Pr}\left(\alpha_{x} \geq \alpha_{x}^{*} \mid \alpha=\breve{\alpha}\right) E\left(\pi_{x} \mid \alpha_{x} \geq \alpha_{x}^{*} \cap \alpha=\breve{\alpha}\right)=\delta f_{e x}
$$

Equation 22 can be rewritten as follows:

$$
\begin{array}{r}
\operatorname{Pr}\left(\beta \alpha+\varepsilon \geq \alpha_{x}^{*} \mid \alpha=\breve{\alpha}\right) E\left(\pi_{x} \mid \alpha_{x} \geq \alpha_{x}^{*} \cap \alpha=\breve{\alpha}\right)=\delta f_{e x} \\
\operatorname{Pr}\left(\varepsilon \geq \alpha_{x}^{*}-\beta \breve{\alpha}\right)\left[E\left(\frac{r_{x}}{\sigma} \mid \alpha_{x} \geq \alpha_{x}^{*} \cap \alpha=\breve{\alpha}\right)-f_{x}\right]=\delta f_{e x} \\
\left(1-T\left(\alpha_{x}^{*}-\beta \breve{\alpha}\right)\right) f_{x}\left[\frac{\check{\alpha}_{x}\left(\alpha_{x}^{*}, \breve{\alpha}\right)}{\alpha_{x}^{*}}-1\right]=\delta f_{e x}
\end{array}
$$

With $\check{\alpha}_{x}\left(\alpha_{x}^{*}, \breve{\alpha}\right)$ the expected exporting taste parameter for a firm that just enters the export market, so with domestic taste parameter $\breve{\alpha}$ :

$$
\begin{aligned}
\check{\alpha}_{x}\left(\alpha_{x}^{*}, \breve{\alpha}\right) & =\frac{1}{\int_{\alpha_{x}^{*}}^{\infty} t\left(\alpha_{x}-\beta \breve{\alpha}\right) d \alpha_{x}} \int_{\alpha_{x}^{*}}^{\infty} \alpha_{x} t\left(\alpha_{x}-\beta \breve{\alpha}\right) d \alpha_{x}=\frac{\int_{\alpha_{x}^{*}-\beta \breve{\alpha}}^{\infty}(\varepsilon+\beta \breve{\alpha}) t(\varepsilon) d \alpha_{x}}{1-T\left(\alpha_{x}^{*}-\beta \breve{\alpha}\right)} \\
& =\beta \breve{\alpha}+\frac{\int_{\alpha_{x}^{*}-\beta \breve{\alpha}}^{\infty} \varepsilon t(\varepsilon) d \alpha_{x}}{1-T\left(\alpha_{x}^{*}-\beta \breve{\alpha}\right)}
\end{aligned}
$$

Proposition 1 There is a unique equilibrium for $\alpha^{*}, \alpha_{x}^{*}, \breve{\alpha}$ and $\tilde{\pi}$ in the model. 
Appendix 1 shows that Eqs. (13), (19), (21), and (23) lead to a unique equilibrium for these variables. Like in the closed economy there is a steady state of entry and exit. The number of firms producing for the domestic market can be derived as in the closed economy from the steady state equations and the labor market equilibrium equations (details in Appendix 2):

$$
N=\frac{L}{\sigma\left(\tilde{\pi}+f+\operatorname{Pr}\left(\alpha \geq \breve{\alpha} \mid \alpha \geq \alpha^{*}\right)\left[\operatorname{Pr}\left(\alpha_{x} \geq \alpha_{x}^{*} \mid \alpha \geq \breve{\alpha}\right) f_{x}+\delta f_{e x}\right]\right)}
$$

Using Eq. (25) the number of firms can be calculated as all the cutoff parameters necessary to calculate the variables on the RHS of (25) are known once Eqs. (13), (19), (21), and (23) are solved.

Welfare per worker is equal to the inverse of the price index. The price index is defined as:

$$
P=\left[N \int_{\alpha^{*}}^{\infty} \alpha\left(a \frac{\sigma}{\sigma-1}\right)^{1-\sigma} \mu(\alpha) d \alpha+N_{x} \int_{\alpha_{x}^{*}}^{\infty} \alpha\left(a \tau \frac{\sigma}{\sigma-1}\right)^{1-\sigma} h(\alpha) d \alpha\right]^{\frac{1}{1-\sigma}}
$$

And it can be rewritten as:

$$
P=N_{t}^{\frac{1}{1-\sigma}} \widetilde{\alpha}_{t}^{\frac{1}{1-\sigma}} a \frac{\sigma}{\sigma-1}
$$

With average popularity $\widetilde{\alpha}_{t}$ and the number of available varieties $N_{t}$ in a country equal to:

$$
\begin{gathered}
\widetilde{\alpha}_{t}=\frac{1}{N_{t}}\left[N \widetilde{\alpha}+N_{x} \tau^{1-\sigma} \widetilde{\alpha}_{x}\right] \\
N_{t}=N+N_{x}
\end{gathered}
$$

For welfare evaluation, the price index can also be written as: ${ }^{10}$

$$
P=\left(\frac{L}{\sigma f}\right)^{\frac{1}{1-\sigma}} a \frac{\sigma}{\sigma-1}\left(\alpha^{*}\right)^{\frac{1}{1-\sigma}}
$$

\section{Effects of changed trade costs}

There are three types of trade costs, the iceberg trade costs $\tau$, sunk export costs $f_{e x}$ and fixed export costs $f_{x}$. This section discusses the effects of changes in each of these types of trade costs on the different cutoff popularity levels $\alpha^{*}, \alpha_{x}^{*}$, $\breve{\alpha}$, on the probability of entering the export market conditional upon entering the domestic market, $\operatorname{Pr}\left(\alpha \geq \breve{\alpha} \mid \alpha \geq \alpha^{*}\right)$, and on the probability of profitable exporting conditional upon entry in the export market (success rate in the export market), $\operatorname{Pr}\left(\alpha_{x} \geq \alpha_{x}^{*} \mid \alpha \geq \breve{\alpha}\right)$. Most results are derived analytically

${ }^{10} \mathrm{Using} \frac{\widetilde{\alpha}_{t}}{\alpha^{*}}=\frac{r\left(\widetilde{\alpha}_{t}\right)}{r\left(\alpha^{*}\right)}=\frac{L / N}{\sigma f}$. 
without specifying a distribution for $\alpha$ and $\varepsilon$. But some effects cannot be determined analytically and the results from a simulation will be reported. In the simulation a truncated normal distribution for domestic popularity $\alpha$ (truncated at 0 ) and a normal distribution for $\varepsilon$ are assumed. Simulation results are robust to different choices of parameter values. ${ }^{11}$ Appendix 4 discusses the simulation setup, the choice of baseline values and robustness checks.

The results of the first comparative statics exercise, on iceberg trade $\cos t s \tau$, are pointed out in the following proposition:

Proposition 2 Lower iceberg trade costs $\tau$ lead to a higher domestic cutoff popularity $\alpha^{*}$ and a lower cutoff popularity for entrance into the export market $\breve{\alpha}$ and for success in the export market $\alpha_{x}^{*}$. The probability of entrance into the export market, $\operatorname{Pr}\left(\alpha \geq \breve{\alpha} \mid \alpha \geq \alpha^{*}\right)$ rises with a lower $\tau$.

Appendix 3.1 contains the proofs for these results. The effects are as expected. Lower iceberg trade costs make exporting more profitable and therefore the cutoff level for success in the export market $\alpha_{x}^{*}$ declines. As a result, the profit conditional upon successful entry, $\tilde{\pi}$, rises. To restore the free entry condition, Eq. (13), the probability to enter the export market successfully thus has to decline and therefore the domestic cutoff level $\alpha^{*}$ has to increase. ${ }^{12}$ The cutoff level to start exporting declines with lower iceberg trade costs, because expected profitability from exporting rises.

The probability of success in the export market, $\operatorname{Pr}\left(\alpha_{x} \geq \alpha_{x}^{*} \mid \alpha \geq \breve{\alpha}\right)$, cannot be determined analytically. Table 1 displays the effects of changed iceberg trade costs on the probability of exporting and the success rate of exporting calculated from simulations using the baseline values. The probability of success in the export market rises with lower trade costs. If a larger distance between trading partners would exclusively affect the iceberg trade costs, this model would imply that trade over a larger distance should have a lower success rate. However, it is likely that distance is not only related to iceberg trade costs, but also to fixed and sunk export costs. Next, the effects of lower sunk export costs $f_{\text {ex }}$ are evaluated.

Proposition 3 Lower sunk exports costs $f_{\text {ex }}$ lead to a higher domestic cutoff level $\alpha^{*}$, a lower cutoff level to start exporting $\breve{\alpha}$ and a higher cutoff level for successful entry into the export market $\alpha_{x}^{*}$. The probability to start exporting rises with lower sunk export costs, but the success rate of exporting declines.

\footnotetext{
${ }^{11}$ In particular, the robustness checks consist of rerunning the simulations varying the parameters in the model one at a time. The signs of the effects stay the same as in the simulations with the baseline values for the parameters. Robustness with respect to distributional assumptions of $\alpha$ and $\varepsilon$ are not verified due to computational problems. So in this regard simulation results should be treated with caution.

${ }^{12}$ As Melitz (2003) points out the mechanism driving this effect is increased competition for scarce labor resources as a result of the increased profitability, which drives up the real wage in the economy.
} 
Table 1 Simulation results of changes in trade costs

\begin{tabular}{lccccc}
\hline$\tau$ & 1 & 1.1 & 1.2 & 1.3 & 1.4 \\
$\operatorname{Pr}($ Exp $)$ & 0.69 & 0.36 & 0.14 & 0.03 & 0.00 \\
$\operatorname{Pr}($ Succ $)$ & 0.60 & 0.63 & 0.66 & 0.70 & 0.75 \\
$f_{\text {ex }}$ & 10 & 11 & 12 & 13 & 14 \\
$\operatorname{Pr}($ Exp $)$ & 0.14 & 0.12 & 0.10 & 0.08 & 0.07 \\
$\operatorname{Pr}($ Succ $)$ & 0.66 & 0.69 & 0.71 & 0.73 & 0.75 \\
$f_{x}$ & 1 & 1.1 & 1.2 & 1.3 & 1.4 \\
$\operatorname{Pr}($ Exp $)$ & 0.14 & 0.10 & 0.07 & 0.04 & 0.03 \\
$\operatorname{Pr}($ Succ $)$ & 0.66 & 0.65 & 0.65 & 0.64 & 0.64 \\
$\beta$ & 0.50 & 0.55 & 0.60 & 0.65 & 0.70 \\
$\operatorname{Pr}($ Exp $)$ & 0.14 & 0.18 & 0.23 & 0.28 & 0.32 \\
$\operatorname{Pr}($ Succ $)$ & 0.66 & 0.61 & 0.57 & 0.54 & 0.50 \\
\hline
\end{tabular}

The first, fourth and seventh row show the different values of iceberg trade costs $\tau$ sunk export costs $f_{e x}$ and fixed export costs $f_{x}$ respectively. The the two rows below these rows show for each parameter the different values of the probability of exporting and the probability of success in the export market. The simulation for each of the parameters consist of a stepwise increase of the parameter by $10 \%$ in each step.

Appendix 3.2 contains the proof of these results. Lower sunk export costs raise expected profit. To restore the ex ante zero profit condition, the cutoff cost level of both domestic and exporting production will have to increase. At the same time it becomes cheaper to start exporting and therefore the cutoff level to start exporting declines. The implication is that more firms start to export, but a lower fraction of them will be successful.

Finally, the effect of lower fixed export costs $f_{x}$ can be calculated.

Proposition 4 Lower fixed export costs cause a higher domestic popularity cutoff level $\alpha^{*}$, a lower cutoff level to start exporting $\breve{\alpha}$ and a lower cutoff level for successful exporting $\alpha_{x}^{*}$. The probability to start exporting rises with lower fixed export costs.

The proof is in Appendix 3.3. Lower fixed export costs raise the expected profits from exporting. This means that also less profitable firms can stay in the export market: the cutoff level for successful exporting $\alpha_{x}^{*}$ declines. The higher exporting profitability also implies a lower cutoff level to start exporting $\breve{\alpha}$. The domestic cutoff level has to rise to restore the free entry condition. As a result, the probability to start exporting rises. The effect on the probability of success in the exporting market cannot be determined analytically. The simulation results reported in Table 1 make clear that the probability of success in the exporting market increase with lower fixed export costs.

It is interesting to perform also a comparative statics analysis on $\beta$, a measure for the similarity of tastes across countries. Predictions on the probability of exporting and the probability of export success could be easily confronted with empirics, using the data on cultural similarity in Felbermayr and Toubal (2010) for example. As shown in Appendix 3.4 the effect of a change in $\beta$ is ambiguous on all the cutoff levels $\alpha^{*}, \alpha_{x}^{*}$ and $\breve{\alpha}$ and thus also on the probability of exporting and exporting success. The simulation results displayed in Table 1 
show that a larger $\beta$ raises the probability of starting to export, but decreases the probability of export success.

The effects of the different types of trade liberalizations are summarized in Table 2. Signs with superscripted 1 are determined in simulations. The effects of lower iceberg trade costs on the different variables are as expected. It becomes easier to export and ex ante expected profit rises leading to a reallocation effect that shifts up the cutoff popularity in the domestic market. Comparing the effects of lower fixed exports costs and sunk export costs provides interesting insights. Both lead to higher ex ante expected profit leading to more entry, more competition for scarce labor resources and therefore a higher cutoff popularity level. But the effects on the two exporting cutoff levels are opposite. Lower fixed exports costs decrease the cutoff level of successful exporting and the cutoff level of entrance into the export market, whereas lower sunk export costs lead to a higher cutoff level of successful exporting and a lower cutoff level of export entrance. The implication is that both lower sunk export costs and lower fixed export costs lead to a larger probability of entrance into the export market. Instead lower fixed export costs increase the probability of success in the export market, whereas lower sunk export costs decrease the probability of successful exporting.

The different impact of changes in sunk and fixed export costs can be explained as follows: lower fixed export costs make the operational profits from exporting higher. Therefore, more firms are able to successfully export now. Also the domestic threshold to start exporting declines, as the expected profits are larger. Lower sunk export costs instead do not affect the operational profits from exporting. They are paid once and do not reappear after that. Still, ex ante expected profits rise when sunk export costs decline. This implies that the cutoff level both for success in the domestic and the export market has to rise to restore the free entry condition.

The implication of these effects is that the probability to enter the export market increases for both lower fixed and sunk export costs. It becomes more attractive to try to enter the export market. Instead the probability to have success in the export market declines with lower sunk entry costs, because more firms try to enter the export market, whereas the cutoff level to be successful is higher. The probability of success in the export market rises with lower fixed export costs. More firms try to enter the export market, but the simulations show that the hurdle to sell profitably in the export market declines even more, making it more likely to be successful in the export market.

Applying Eq. (29), the welfare effects of lower trade costs can be determined. The following result can be derived:

Table 2 Summary of signs of marginal effects of changes in trade costs on cutoff values and exporting and exporting success probabilities

\begin{tabular}{llll}
\hline & $\tau$ & $f_{x}$ & $f_{\text {ex }}$ \\
\hline$\alpha^{*}$ & - & - & - \\
$\breve{\alpha}$ & + & + & + \\
$\alpha_{x}^{*}$ & + & + & - \\
$\operatorname{Pr}($ Exporting $)$ & - & - & - \\
$\operatorname{Pr}($ Success $)$ & -1 & $-{ }^{1}$ & + \\
\hline
\end{tabular}


Proposition 5 Lower iceberg trade costs $\tau$, lower sunk export costs $f_{\text {ex }}$ and lower fixed export costs $f_{x}$ all lead to an increase in welfare.

Lower trade costs of each of the three types lead to a higher domestic cutoff popularity $\alpha^{*}$. Applying Eq. (29), this implies that welfare rises in all three cases. ${ }^{13}$ The result is remarkable for the decline in sunk export costs. Lower sunk export costs raise the probability of entry but decrease the probability of success in the export market. Hence, they eat away valuable resources without leading to additional production. That welfare still rises is due to the Melitztype structure of the model. An increasing demand for valuable resources, even if they do not lead to more production, is always welfare enhancing. The higher demand for resources bids up real wages and squeezes the least productive firms out of the market and so is actually the main driving force for a welfare improvement.

\section{Concluding remarks}

This paper modeled export uncertainty due to lack of information among firms about the popularity of their variety in the export market to explain the large amount of firms exiting the export market shortly after entry. In other work (by Baldwin 1988 and Irarrazabal and Opromolla 2006 for example) shocks to variables affecting profitability like productivity are used to account for exit from the export market. The explanation put forward in this paper is supported by empirical work that shows that a large fraction of exit from the export market is shortly after entry. The network view on international trade as proposed by Rauch (1999) and Rauch and Watson (2003) provides an alternative explanation for quick exit of firms from the export market: buyers switch suppliers often and the old seller drops out of the export market.

The model in this paper predicts that changes in sunk export costs and in fixed export costs have opposite effects on the probability of entry into the export market and successful entry. Lower sunk export costs raise the probability of entry into the export market, but decrease the rate of export success. Lower fixed export costs raise both the probability of export entry and the probability of export success.

Work in the present paper can be extended in various directions. Firstly, an n-country version of the model could be used to estimate the parameters of the model with firm-level data on exporting. Secondly, the work of Nguyen (2008) could be combined with the current work. In such a model firms could learn about the popularity of their variety by incurring sunk export costs, but also by small sales. An extended model could allow for the possibility to approach a foreign market in two ways: through market experimentation along with small-

\footnotetext{
${ }^{13} \mathrm{An}$ implication is that total production will rise, as total production (utility $U$ ) is equal to $L$ divided by $P$.
} 
scale sales and through market flooding along with incurring large market research costs, product development and marketing costs. Such a model could generate predictions on what determines how firms enter a foreign market, for example firm size and market size of the importing country. A third possible extension is empirical and could try to find ways to differentiate empirically between the tastes cum lack of information view and the network view and between the small sales approach to enter foreign markets and the sunk cost approach followed in this paper, which all provide an explanation for exporting uncertainty and quick exit from the export market. Such empirical work would require detailed firm level data which contains information on how firms enter foreign markets, for example through import agents, through direct sales to customers or through sales subsidiaries. The choice of certain export modes could be related to covariates like firm size and importer market size to test predictions from a theoretical model as mentioned above where firms have the possibility to enter the export market in different ways.

Open Access This article is distributed under the terms of the Creative Commons Attribution Noncommercial License which permits any noncommercial use, distribution, and reproduction in any medium, provided the original author(s) and source are credited.

\section{Appendix 1: Unique equilibrium open economy}

The equilibrium in the model is found by combining Eqs. (13), (19), (21), and (23) and solving for the three unknowns $\alpha^{*}, \alpha_{x}^{*}, \breve{\alpha}$. Merging Eqs. (13) and (21) and rewriting, the model consists of the following three equations in three unknowns:

$$
\begin{gathered}
\alpha_{x}^{*}=\frac{f_{x}}{f} \tau^{\sigma-1} \alpha^{*} \\
f j\left(\alpha^{*}\right)+(1-G(\breve{\alpha}))\left[f_{x} j_{x}\left(\alpha_{x}^{*}, \breve{\alpha}\right)-\delta f_{e x}\right]=\delta f_{e} \\
f_{x} i_{x}\left(\alpha_{x}^{*}, \breve{\alpha}\right)=\delta f_{e x}
\end{gathered}
$$

With $j(\alpha), j_{x}\left(\alpha_{x}, \breve{\alpha}\right)$ and $i_{x}\left(\alpha_{x}, \breve{\alpha}\right)$ defined as:

$$
\begin{aligned}
j(a) & =(1-G(\alpha))\left[\frac{\widetilde{\alpha}(\alpha)}{\alpha}-1\right] \\
j_{x}\left(\alpha_{x}, \breve{\alpha}\right) & =\left(1-H\left(\alpha_{x}, \breve{\alpha}\right)\right)\left[\frac{\widetilde{\alpha}_{x}\left(\alpha_{x}, \breve{\alpha}\right)}{\alpha_{x}}-1\right] \\
i_{x}\left(\alpha_{x}, \breve{\alpha}\right) & =\left(1-F\left(\alpha_{x}-\beta \breve{\alpha}\right)\right)\left[\frac{\check{\alpha}\left(\alpha_{x}, \breve{\alpha}\right)}{\alpha_{x}}-1\right]
\end{aligned}
$$


Uniqueness of the equilibrium is shown as follows. Equations 30-32 are log differentiated with respect to the three unknowns $\alpha^{*}, \breve{\alpha}$ and $\alpha_{x}^{*}$. Variables with a hat will indicate relative changes. It will become clear that (30) and (31) are independent of the level of $\breve{\alpha}$. The log differentiation of (30) is then substituted into (31) to show that the LHS of (31) rises monotonically in $\alpha^{*}$. This implies a unique solution. The log differentiation of (32) makes clear that there is a unique corresponding value of $\breve{\alpha}$.

Log differentiating Eqs (30) and (31) with respect to $\alpha^{*}, \breve{\alpha}$ and $\alpha_{x}^{*}$ gives:

$$
\begin{gathered}
\widehat{\alpha}_{x}^{*}=\widehat{\alpha}^{*} \\
f \frac{\partial j\left(\alpha^{*}\right)}{\partial \alpha^{*}} \alpha^{*} \widehat{\alpha}^{*}-g(\breve{\alpha})\left[f_{x} j_{x}\left(\alpha_{x}^{*}, \breve{\alpha}\right)-\delta f_{e x}\right] \breve{\alpha} \widehat{\alpha}+f_{x} \frac{\partial j_{x}\left(\alpha_{x}^{*}, \breve{\alpha}\right)}{\partial \alpha_{x}^{*}} \alpha_{x}^{*} \widehat{\alpha}_{x}^{*} \\
+(1-G(\breve{\alpha})) f_{x} \frac{\partial j_{x}\left(\alpha_{x}^{*}, \breve{\alpha}\right)}{\partial \breve{\alpha}} \breve{\alpha} \widehat{\alpha}=0
\end{gathered}
$$

It can be proved that $\frac{\partial j(\alpha)}{\partial \alpha}=-\frac{1}{\alpha}[j(\alpha)+(1-G(\alpha))]<0$ and that $\frac{\partial j_{x}\left(\alpha_{x}, \breve{\alpha}\right)}{\partial \alpha_{x}^{*}}=$ $-\frac{1}{\alpha_{x}}\left[j_{x}\left(\alpha_{x}, \breve{\alpha}\right)+\left(1-H\left(\alpha_{x}, \breve{\alpha}\right)\right)\right]<0$. The derivation is similar to the derivation in Appendix B of Melitz (2003) and available upon request. Furthermore, it can be proved that the two terms in $\widehat{\hat{\alpha}}$ cancel each other out. The derivation is lengthy but straightforward and available upon request. Therefore, using Eq. (33), Eq. (34) can be rewritten as:

$$
-f\left[j\left(\alpha^{*}\right)+\left(1-G\left(\alpha^{*}\right)\right)\right] \widehat{\alpha}^{*}-(1-G(\breve{\alpha})) f_{x}\left[j_{x}\left(\alpha_{x}^{*}, \breve{\alpha}\right)+\left(1-H\left(\alpha_{x}^{*}, \breve{\alpha}\right)\right)\right] \widehat{\alpha}_{x}^{*}=0
$$

Equation 35 shows that the LHS of (31) is monotonically increasing in $\alpha^{*}$. Furthermore it can be shown that $\lim _{\alpha \rightarrow 0} j(\alpha)=\infty$. This implies a unique solution for $\alpha^{*}$ and $\alpha_{x}^{*}$.

Log differentiating Eq. (32) with respect to $\alpha_{x}^{*}$ and $\breve{\alpha}$ gives the following expression (derivation available upon request):

$$
\left(1-T\left(\alpha_{x}^{*}-\beta \breve{\alpha}\right)\right) \frac{\beta \breve{\alpha}}{\alpha_{x}^{*}} \widehat{\widetilde{\alpha}}-\left[i_{x}\left(\alpha_{x}^{*}, \breve{\alpha}\right)+\left(1-T\left(\alpha_{x}^{*}-\beta \breve{\alpha}\right)\right)\right] \widehat{\alpha}_{x}^{*}=0
$$

Equation 36 shows $\breve{\alpha}$ that rises monotonically in $\alpha_{x}^{*}$ implying a unique equilibrium value for $\breve{\alpha}$ corresponding to the equilibrium value $\alpha_{x}^{*}$. Eq. (36)) can be simplified to generate an expression useful for the comparative statics later on:

$$
\widehat{\widehat{\alpha}}=\frac{\check{\alpha}_{x}}{\beta \breve{\alpha}} \widehat{\alpha}_{x}^{*}=\left(1+\frac{\int_{\alpha_{x}^{*}-\beta \breve{\alpha}}^{\infty} \varepsilon t(\varepsilon) d \alpha_{x}}{1-T\left(\alpha_{x}^{*}-\beta \breve{\alpha}\right)}\right) \widehat{\alpha}_{x}^{*}
$$




\section{Appendix 2: Derivation number of firms}

Labor can be allocated to four different tasks, domestic production, domestic entry, exporting production and exporting entry listed in this sequence in Eq. (38):

$$
L=L_{p}+L_{e}+L_{p, x}+L_{e, x}
$$

The labor market equilibria for production in the domestic and exporting markets are defined as:

$$
\begin{gathered}
L_{p}=N \widetilde{r}_{d}-N \widetilde{\pi}_{d} \\
L_{p, x}=N_{x} \widetilde{r}_{x}-N_{x} \widetilde{\pi}_{x}
\end{gathered}
$$

$N$ and $N_{x}$ are the number of firms producing for respectively the domestic and the exporting market. The labor market equilibria for market exploration to enter the domestic market and the exporting market are given respectively by:

$$
\begin{gathered}
L_{e}=f_{e} N_{e} \\
L_{e, x}=f_{e x} N_{e, x}
\end{gathered}
$$

$N_{e}$ and $N_{e, x}$ are the number of firms trying to enter the domestic market and the export market, respectively. Entry and exit on both the domestic and the exporting market has to be equal in steady state. This implies:

$$
\begin{gathered}
N_{e} \operatorname{Pr}\left(\alpha \geq \alpha^{*}\right)=\delta N \\
N_{e, x} \operatorname{Pr}\left(\alpha_{x} \geq \alpha_{x}^{*} \mid \alpha \geq \breve{\alpha}\right)=\delta N_{x}
\end{gathered}
$$

Adding the four labor market equilibrium conditions, i.e. substituting Eqs. (39)-(44) into Eq. (38), gives:

$$
\begin{aligned}
L & =N \widetilde{r}_{d}-N \tilde{\pi}_{d}+N \tilde{\pi}+N_{x} \widetilde{r}_{x}-N_{x} \widetilde{\pi}_{x}+\frac{f_{e x} \delta N_{x}}{\operatorname{Pr}\left(\alpha_{x} \geq \alpha_{x}^{*} \mid \alpha \geq \breve{\alpha}\right)} \\
& =N\left(\widetilde{r}_{d}-\tilde{\pi}_{d}+\tilde{\pi}+\frac{N_{x}}{N}\left(\widetilde{r}_{x}-\tilde{\pi}_{x}+\frac{f_{e x} \delta}{\operatorname{Pr}\left(\alpha_{x} \geq \alpha_{x}^{*} \mid \alpha \geq \breve{\alpha}\right)}\right)\right) \\
& =N\left(\widetilde{r}_{d}-\tilde{\pi}_{d}+\tilde{\pi}+\frac{1-G(\breve{\alpha})}{1-G\left(\alpha^{*}\right)}\left(1-H\left(\alpha_{x}^{*}, \breve{\alpha}\right)\right)\left(\widetilde{r}_{x}-\widetilde{\pi}_{x}+\frac{f_{e x} \delta}{\left(1-H\left(\alpha_{x}^{*}, \breve{\alpha}\right)\right)}\right)\right) \\
& =N\left(\widetilde{r}_{d}+\frac{1-G(\breve{\alpha})}{1-G\left(\alpha^{*}\right)}\left(1-H\left(\alpha_{x}^{*}, \breve{\alpha}\right)\right) \widetilde{r}_{x}\right)=N \widetilde{r}=N_{t} r\left(\widetilde{\alpha}_{t}\right)
\end{aligned}
$$


$\widetilde{\alpha}_{t}$ and $N_{t}$ are defined in Eqs. (27) and (28). Average revenues in Eq. (45) can be rewritten to find the following expression for the number of domestic producing firms:

$$
N=\frac{L}{\sigma\left(\tilde{\pi}+f+\frac{1-G(\breve{\alpha})}{1-G\left(\alpha^{*}\right)}\left(\delta f_{e x}+\left(1-H\left(\alpha_{x}^{*}, \breve{\alpha}\right)\right) f_{x}\right)\right)}
$$

\section{Appendix 3: Effect of changed trade costs}

This appendix derives the effects of changes in the three types of trade costs $\tau, f_{x}$ and $f_{e x}$ on the three cutoff values $\alpha^{*}, \alpha_{x}^{*}, \breve{\alpha}$ and on the probabilities of exporting and the success rate of exporting, $\operatorname{Pr}\left(\alpha \geq \breve{\alpha} \mid \alpha \geq \alpha^{*}\right)$ and $\operatorname{Pr}\left(\alpha_{x} \geq \alpha_{x}^{*} \mid \alpha \geq \breve{\alpha}\right)$ respectively. $\eta_{y, x}$ indicates the elasticity of $y$ with respect to $x$.

Appendix 3.1: Changed iceberg trade costs

Equations 30-22 can be log differentiated with respect to $\tau, \alpha^{*}, \alpha_{x}^{*}, \breve{\alpha}$. Only (30) contains $\tau$, so the log differentiated equations of (31) and (22) are given in Eqs. (35) and (37) respectively. The log differentiation of (30) becomes:

$$
\widehat{\alpha}_{x}^{*}=(\sigma-1) \widehat{\tau}+\widehat{\alpha}^{*}
$$

Combining Eqs. (47), (35) and (37), one can solve for $\widehat{\alpha}^{*}, \widehat{\alpha}$ and $\widehat{\alpha}_{x}^{*}$ as a function $\widehat{\tau}$ :

$$
\begin{aligned}
& \widehat{\alpha}^{*}=-\frac{(\sigma-1) f_{x}\left(1-H\left(\alpha_{x}^{*}, \breve{\alpha}\right)\right) \frac{\widetilde{\alpha}_{x}}{\alpha_{x}^{*}}}{f\left(1-G\left(\alpha^{*}\right)\right) \frac{\widetilde{\alpha}}{\alpha^{*}}+f_{x}\left(1-H\left(\alpha_{x}^{*}, \breve{\alpha}\right)\right) \frac{\widetilde{\alpha}_{x}}{\alpha_{x}^{*}} \widehat{\tau}} \\
& \widehat{\alpha}_{x}^{*}=\frac{(\sigma-1) f\left(1-G\left(\alpha^{*}\right)\right) \frac{\widetilde{\alpha}}{\alpha^{*}}}{f\left(1-G\left(\alpha^{*}\right)\right) \frac{\widetilde{\alpha}}{\alpha^{*}}+f_{x}\left(1-H\left(\alpha_{x}^{*}, \breve{\alpha}\right)\right) \frac{\widetilde{\alpha}_{x}}{\alpha_{x}^{*}} \widehat{\tau}} \\
& \widehat{\alpha}=\frac{\check{\alpha}_{x}}{\beta \breve{\alpha}} \frac{(\sigma-1) f\left(1-G\left(\alpha^{*}\right)\right) \frac{\widetilde{\alpha}}{\alpha^{*}}}{f\left(1-G\left(\alpha^{*}\right)\right) \frac{\widetilde{\alpha}}{\alpha^{*}}+f_{x}\left(1-H\left(\alpha_{x}^{*}, \breve{\alpha}\right)\right) \frac{\widetilde{\alpha}_{x}^{*}}{\alpha_{x}^{*}} \widehat{\tau}}
\end{aligned}
$$

Hence, $\eta_{\alpha^{*}, \tau}<0, \eta_{\alpha_{x}^{*}, \tau}>0$ and $\eta_{\breve{\alpha}, \tau}>0$. The probability of exporting and the success rate of exporting can be log differentiated with respect to the three cutoff values:

$$
d \ln \operatorname{Pr}\left(\alpha \geq \breve{\alpha} \mid \alpha \geq \alpha^{*}\right)=-g(\breve{\alpha}) \breve{\alpha} \widehat{\alpha}+g\left(\alpha^{*}\right) \alpha^{*} \widehat{\alpha}^{*}
$$

$$
\begin{aligned}
& d \ln \operatorname{Pr}\left(\alpha_{x} \geq \alpha_{x}^{*} \mid \alpha \geq \breve{\alpha}\right) \\
& \quad=-h\left(\alpha_{x}^{*}, \breve{\alpha}\right) \alpha_{x}^{*} \widehat{\alpha}_{x}^{*}+\frac{g(\breve{\alpha})}{1-G(\breve{\alpha})}\left(\left(1-H\left(\alpha_{x}^{*}, \breve{\alpha}\right)\right)-\left(1-T\left(\alpha_{x}^{*}-\beta \breve{\alpha}\right)\right)\right) \widehat{\alpha}
\end{aligned}
$$


Notice that in Eq. (49), $\left(1-H\left(\alpha_{x}^{*}, \breve{\alpha}\right)\right) \geq\left(1-T\left(\alpha_{x}^{*}-\beta \breve{\alpha}\right)\right)$, because the probability of successful exporting is larger for firms with a larger domestic taste parameter. Substituting the relative changes in cutoff parameters into Eqs. (48) and (49) shows that lower iceberg trade costs leads to a larger probability of exporting. The sign of the effect on the success rate of exporting cannot be determined:

$$
\frac{\partial \ln \operatorname{Pr}\left(\alpha \geq \breve{\alpha} \mid \alpha \geq \alpha^{*}\right)}{\partial \ln \tau}=-g(\breve{\alpha}) \breve{\alpha} \varepsilon_{\breve{\alpha}, \tau}+g\left(\alpha^{*}\right) \alpha^{*} \eta_{\alpha^{*}, \tau}>0
$$

$$
\begin{aligned}
& \frac{\partial \ln \operatorname{Pr}\left(\alpha_{x} \geq \alpha_{x}^{*} \mid \alpha \geq \breve{\alpha}\right)}{\partial \ln \tau} \\
& \quad=-h\left(\alpha_{x}^{*}, \breve{\alpha}\right) \alpha_{x}^{*} \eta_{\alpha_{x}^{*}, \tau}+\frac{g(\breve{\alpha})}{1-G(\breve{\alpha})}\left(\left(1-H\left(\alpha_{x}^{*}, \breve{\alpha}\right)\right)-\left(1-T\left(\alpha_{x}^{*}-\beta \breve{\alpha}\right)\right)\right) \eta_{\breve{\alpha}, \tau}
\end{aligned}
$$

\section{Appendix 3.2: Changed sunk export costs}

Equations 30-32 can be log differentiated with respect to $\alpha^{*}, \alpha_{x}^{*}, \breve{\alpha}$ and $f_{e x}$. The $\log$ differentiation of Eq. (30) is given by (33). The log differentiations of (31) and (32) are given respectively by:

$$
\begin{gathered}
-f\left(1-G\left(\alpha^{*}\right)\right) \frac{\widetilde{\alpha}}{\alpha^{*}} \widehat{\alpha_{x}^{*}}-f_{x}(1-G(\breve{\alpha}))\left(1-H\left(\alpha_{x}^{*}, \breve{\alpha}\right)\right) \frac{\widetilde{\alpha}_{x}}{\alpha_{x}^{*}} \widehat{\alpha_{x}^{*}} \\
-(1-G(\breve{\alpha})) \delta f_{e x} \widehat{f_{e x}}=0 \\
f_{x}\left(1-F\left(\alpha_{x}^{*}-\beta \breve{\alpha}\right)\right) \frac{\beta \breve{\alpha}}{\alpha_{x}^{*}} \widehat{\vec{\alpha}}-f_{x}\left(1-F\left(\alpha_{x}^{*}-\beta \breve{\alpha}\right)\right) \frac{\check{\alpha}_{x}}{\alpha_{x}^{*}} \widehat{\alpha_{x}^{*}}=\delta f_{e x} \widehat{f_{e x}}
\end{gathered}
$$

Solving for $\widehat{\alpha^{*}}, \widehat{\alpha_{x}^{*}}$ and $\widehat{\alpha}$ from Eqs. (33), (50) and (51) generates:

$$
\begin{gathered}
\widehat{\alpha^{*}}=\widehat{\alpha_{x}^{*}}=\frac{(1-G(\breve{\alpha})) \delta f_{e x}}{f\left(1-G\left(\alpha^{*}\right)\right) \frac{\widetilde{\alpha}}{\alpha^{*}}+f_{x}(1-G(\breve{\alpha}))\left(1-H\left(\alpha_{x}^{*}, \breve{\alpha}\right)\right) \frac{\widetilde{\alpha}_{x}}{\alpha_{x}^{*}} \widehat{f_{e x}}} \quad(52) \\
\widehat{\alpha}=\frac{f\left(1-G\left(\alpha^{*}\right)\right) \frac{\widetilde{\alpha}}{\alpha^{*}}+f_{x}(1-G(\breve{\alpha}))\left[\left(1-H\left(\alpha_{x}^{*}, \breve{\alpha}\right)\right) \frac{\widetilde{\alpha}_{x}}{\alpha_{x}^{*}}-\left(1-T\left(\alpha_{x}^{*}-\beta \breve{\alpha}\right)\right) \frac{\check{\alpha}_{x}}{\alpha_{x}^{*}}\right]}{\left.f_{x}\left(1-T\left(\alpha_{x}^{*}-\beta \breve{\alpha}\right)\right) \frac{\beta \breve{\alpha}}{\delta f_{e x} \alpha_{x}^{*}}\left[f\left(1-G\left(\alpha^{*}\right)\right) \frac{\widetilde{\alpha}}{\alpha^{*}}+f_{x}(1-G(\breve{\alpha}))\left(1-H\left(\alpha_{x}^{*}, \breve{\alpha}\right)\right)\right) \widetilde{\alpha}_{\alpha_{x}}\right]}
\end{gathered}
$$

Equations 52 and 53 show that $-1<\eta_{\alpha^{*}, f_{e x}}=\eta_{\alpha_{x}^{*}, f_{e x}}<0$ and $\eta_{\check{\alpha}, f_{e x}}>0$. Using Eqs. (48) and (49) this implies that the probability of exporting rises with lower sunk export costs whereas the success rate of exporting declines:

$$
\frac{\partial \ln \operatorname{Pr}\left(\alpha \geq \breve{\alpha} \mid \alpha \geq \alpha^{*}\right)}{\partial \ln f_{e x}}=-g(\breve{\alpha}) \breve{\alpha} \varepsilon_{\breve{\alpha}, f_{e x}}+g\left(\alpha^{*}\right) \alpha^{*} \eta_{\alpha^{*}, f_{e x}}<0
$$




$$
\begin{aligned}
& \frac{\partial \ln \operatorname{Pr}\left(\alpha_{x} \geq \alpha_{x}^{*} \mid \alpha \geq \breve{\alpha}\right)}{\partial \ln f_{e x}} \\
& =-h\left(\alpha_{x}^{*}, \breve{\alpha}\right) \alpha_{x}^{*} \eta_{\alpha_{x}^{*}, f_{e x}}+\frac{g(\breve{\alpha})}{1-G(\breve{\alpha})}\left(\left(1-H\left(\alpha_{x}^{*}, \breve{\alpha}\right)\right)-\left(1-T\left(\alpha_{x}^{*}-\beta \breve{\alpha}\right)\right)\right) \eta_{\breve{\alpha}, f_{e x}}>0
\end{aligned}
$$

\section{Appendix 3.3: Changed fixed export costs}

Equations 30-32 can be $\log$ differentiated with respect to $\alpha^{*}, \alpha_{x}^{*}, \breve{\alpha}$ and $f_{x}$. This generates the following three equations:

$$
\begin{aligned}
& \widehat{\alpha_{x}^{*}}=\widehat{f}_{x}+\widehat{\alpha^{*}} \\
& -f\left(1-G\left(\alpha^{*}\right)\right) \frac{\widetilde{\alpha}}{\alpha^{*}} \widehat{\alpha^{*}}-f_{x}(1-G(\breve{\alpha}))\left(1-H\left(\alpha_{x}^{*}, \breve{\alpha}\right)\right) \frac{\widetilde{\alpha}_{x}}{\alpha_{x}^{*}} \widehat{\alpha_{x}^{*}} \\
& +f_{x}(1-G(\breve{\alpha})) j_{x}\left(\alpha_{x}^{*}, \breve{\alpha}\right) \widehat{f}_{x}=0 \\
& \left(1-F\left(\alpha_{x}^{*}-\beta \breve{\alpha}\right)\right) \frac{\beta \breve{\alpha}}{\alpha_{x}^{*}} \widehat{\bar{\alpha}}-\left(1-T\left(\alpha_{x}^{*}-\beta \breve{\alpha}\right)\right) \frac{\check{\alpha}_{x}}{\alpha_{x}^{*}} \widehat{\alpha_{x}^{*}}+\delta f_{e x} \widehat{f}_{x}=0
\end{aligned}
$$

Solving for $\widehat{\alpha^{*}}$ and $\widehat{\alpha_{x}^{*}}$ from Eqs. (54) and (55) leads to:

$$
\begin{gathered}
\widehat{\alpha^{*}}=-\frac{f_{x}(1-G(\breve{\alpha}))\left(1-H\left(\alpha_{x}^{*}, \breve{\alpha}\right)\right)}{f\left(1-G\left(\alpha^{*}\right)\right) \frac{\widetilde{\alpha}}{\alpha^{*}}+f_{x}(1-G(\breve{\alpha}))\left(1-H\left(\alpha_{x}^{*}, \breve{\alpha}\right)\right) \frac{\widetilde{\alpha}_{x}^{*}}{\alpha_{x}^{*}} \widehat{f}_{x}} \\
\widehat{\alpha_{x}^{*}}=\frac{f\left(1-G\left(\alpha^{*}\right)\right) \frac{\widetilde{\alpha}}{\alpha^{*}}+f_{x}(1-G(\breve{\alpha}))\left(1-H\left(\alpha_{x}^{*}, \breve{\alpha}\right)\right)\left[\frac{\widetilde{\alpha}_{x}}{\alpha_{x}^{*}}-1\right]_{\widetilde{\alpha}_{x}}}{f\left(1-G\left(\alpha^{*}\right)\right) \frac{\widetilde{\alpha}}{\alpha^{*}}+f_{x}(1-G(\breve{\alpha}))\left(1-H\left(\alpha_{x}^{*}, \breve{\alpha}\right)\right) \frac{\widetilde{\alpha}_{x}^{*}}{\alpha_{x}^{*}}}
\end{gathered}
$$

And from (56) and (58), $\widehat{\ddot{\alpha}}$ can be calculated:

$$
\widehat{\vec{\alpha}}=\frac{\alpha_{x}^{*}}{\beta \breve{\alpha}} \frac{f\left(1-G\left(\alpha^{*}\right)\right) \frac{\widetilde{\alpha}}{\alpha^{*}}+f_{x}(1-G(\breve{\alpha}))\left(1-H\left(\alpha_{x}^{*}, \breve{\alpha}\right)\right) \frac{\widetilde{\alpha}_{x}-\check{\alpha}_{x}}{\alpha_{x}^{*}}}{f\left(1-G\left(\alpha^{*}\right)\right) \frac{\widetilde{\alpha}}{\alpha^{*}}+f_{x}(1-G(\breve{\alpha}))\left(1-H\left(\alpha_{x}^{*}, \breve{\alpha}\right)\right) \frac{\widetilde{\alpha}_{x}}{\alpha_{x}^{*}}} \widehat{f}_{x}
$$

Hence, $-1<\eta_{\alpha^{*}, f_{x}}<0,0<\eta_{\alpha_{x}^{*}, f_{x}}<1$ and $\eta_{\breve{\alpha}, f_{x}}>0$. This implies, using (48) and (49), that the probability to start exporting rises, whereas the effect on the success rate of exporting cannot be determined without specifying a distribution of taste parameters:

$$
\frac{\partial \ln \operatorname{Pr}\left(\alpha \geq \breve{\alpha} \mid \alpha \geq \alpha^{*}\right)}{\partial \ln f_{x}}=-g(\breve{\alpha}) \breve{\alpha} \eta_{\breve{\alpha}, f_{x}}+g\left(\alpha^{*}\right) \alpha^{*} \eta_{\alpha^{*}, f_{x}}
$$




$$
\begin{aligned}
\frac{\partial \ln \operatorname{Pr}\left(\alpha_{x} \geq \alpha_{x}^{*} \mid \alpha \geq \breve{\alpha}\right)}{\partial \ln f_{x}}= & -h\left(\alpha_{x}^{*}, \breve{\alpha}\right) \alpha_{x}^{*} \eta_{\alpha_{x}^{*}, f_{x}} \\
& +\frac{g(\breve{\alpha})}{1-G(\breve{\alpha})}\left(\left(1-H\left(\alpha_{x}^{*}, \breve{\alpha}\right)\right)-\left(1-T\left(\alpha_{x}^{*}-\beta \breve{\alpha}\right)\right)\right) \eta_{\breve{\alpha}, f_{x}<0}
\end{aligned}
$$

Appendix 3.4: Changed similarity parameter $\beta$

Equations 30-32 can be log differentiated with respect to $\alpha^{*}, \alpha_{x}^{*}, \breve{\alpha}$ and $\beta$. $\log$ differentiating Eq. (30) leads to (33). Log differentiating Eqs. (31) and (32) generates respectively:

$$
\begin{gathered}
-f\left(1-G\left(\alpha^{*}\right)\right) \frac{\widetilde{\alpha}}{\alpha^{*}} \widehat{\alpha^{*}}-f_{x}(1-G(\breve{\alpha}))\left(1-H\left(\alpha_{x}^{*}, \breve{\alpha}\right)\right) \frac{\widetilde{\alpha}_{x}}{\alpha_{x}^{*}} \widehat{\alpha_{x}^{*}} \\
+f_{x}(1-G(\breve{\alpha}))\left(\frac{1}{\alpha_{x}} \int_{\alpha_{x}}^{\infty} \frac{\xi-\alpha_{x}}{1-G(\breve{\alpha})} g(\breve{\alpha}) t(\xi-\beta \breve{\alpha}) d \xi-j_{x}\left(\alpha_{x}, \breve{\alpha}\right)\right. \\
\left.+\int_{\alpha_{x}}^{\infty} \frac{\xi-\alpha_{x}}{1-G(\breve{\alpha})} \int_{\beta \breve{\alpha}}^{\infty} \frac{1}{\beta} g^{\prime}\left(\frac{x}{\beta}\right) \frac{x}{\beta} t(\xi-x) d x d \xi\right) \widehat{\beta}=0 \\
\left(1-T\left(\alpha_{x}^{*}-\beta \breve{\alpha}\right)\right) \frac{\beta \breve{\alpha}}{\alpha_{x}^{*}} \widehat{\alpha}-\left(1-T\left(\alpha_{x}^{*}-\beta \breve{\alpha}\right)\right) \frac{\check{\alpha}_{x}}{\alpha_{x}^{*}} \widehat{\alpha_{x}^{*}}+\left(1-T\left(\alpha_{x}^{*}-\beta \breve{\alpha}\right)\right) \frac{\beta \breve{\alpha}}{\alpha_{x}^{*}} \widehat{\beta}
\end{gathered}
$$

Combining Eqs. (33), (59) and (60) leads to the following expressions:

$$
\begin{aligned}
\widehat{\alpha^{*}} & =\widehat{\alpha_{x}^{*}} \\
& =\frac{\left(\frac{1}{\alpha_{x}} \int_{\alpha_{x}}^{\infty} \frac{\xi-\alpha_{x}}{1-G(\breve{\alpha})} g(\breve{\alpha}) t(\xi-\beta \breve{\alpha}) d \xi-j_{x}\left(\alpha_{x}, \breve{\alpha}\right)+\int_{\alpha_{x}}^{\infty} \frac{\xi-\alpha_{x}}{1-G(\breve{\alpha})} \int_{\beta \breve{\alpha}}^{\infty} \frac{1}{\beta} g^{\prime}\left(\frac{x}{\beta}\right) \frac{x}{\beta} t(\xi-x) d x d \xi\right)}{\left.\frac{f}{f_{x}} \frac{1-G\left(\alpha^{*}\right)}{1-G(\breve{\alpha})} \frac{\widetilde{\alpha}}{\alpha^{*}}-\left(1-H\left(\alpha_{x}^{*}, \breve{\alpha}\right)\right)\right)_{\frac{\alpha_{x}}{\alpha_{x}^{*}}}} \widehat{\widehat{\beta}}
\end{aligned}
$$

$\widehat{\widehat{\alpha}}=\left(\frac{\check{\alpha}_{x}}{\beta \breve{\alpha}} \frac{\left(\frac{1}{\alpha_{x}} \int_{\alpha_{x}}^{\infty} \frac{\xi-\alpha_{x}}{1-G(\breve{\alpha})} g(\breve{\alpha}) t(\xi-\beta \breve{\alpha}) d \xi-j_{x}\left(\alpha_{x}, \breve{\alpha}\right)+\int_{\alpha_{x}}^{\infty} \frac{\xi-\alpha_{x}}{1-G(\breve{\alpha})} \int_{\beta \breve{\alpha}}^{\infty} \frac{1}{\beta} g^{\prime}\left(\frac{x}{\beta}\right) \frac{x}{\beta} t(\xi-x) d x d \xi\right)}{\frac{f}{f_{x}} \frac{1-G\left(\alpha^{*}\right)}{1-G(\breve{\alpha})} \frac{\widetilde{\alpha}}{\alpha^{*}}-\left(1-H\left(\alpha_{x}^{*}, \breve{\alpha}\right)\right) \frac{\widetilde{\alpha}_{x}}{\alpha_{x}^{*}}}-1\right)$ $\widehat{\beta}=0$

Because the numerator of the coefficient in Eq. (61) contains a positive, a negative and an ambiguous term, the sign of the effect of $\beta$ on $\alpha^{*}$ and $\alpha_{x}^{*}$ 
cannot be determined. As a result also the sign of the effect on $\breve{\alpha}$ cannot be determined.

\section{Appendix 4: Simulations}

To get some insight in the effects of changes in trade costs whose sign cannot be determined analytically, the model is solved numerically. Equations 13, 19, 21, and 23 have to be solved for $\alpha^{*}, \alpha_{x}^{*}, \breve{\alpha}$ and $\tilde{\pi}$. The philosophy behind choosing the baseline parameter values is in line with the choice of parameters in the numerical analysis of Bernard et al. (2007). Baseline parameter values and the corresponding values of the endogenous variables are displayed in Table 3.

The elasticity of substitution $\sigma$ is set at 3.8 following estimates using plantlevel US manufacturing data in Bernard et al. (2003). The parameter value of the sunk entry cost $f_{e}$ scales the mass of firms and without loss of generality $f_{e}$ is set at 10 . Fixed production costs, domestically and in the foreign market, $f$ and $f_{x}$ respectively, are $10 \%$ of the sunk entry cost, 1 . The domestic and exporting fixed costs are equal in the baseline, implying an equal domestic and exporting cutoff taste parameter in the case of zero iceberg trade costs. The death probability $\delta$ rescales the mass of entrants relative to the mass of producing firms and without loss of generality, a value of 0.025 is chosen. Marginal cost $a$ and market size $L$ do not affect the solution of the endogenous variables and just rescale the price index $P$. $a$ is set at 0.5 and $L$ at 100 . Iceberg trade $\cos t$ s $\tau$ are set equal to 1.2 , the case with iceberg trade costs equal to 1 would not be an interesting benchmark.

The parameter indicating the relation between CES weights $\beta$ and the standard deviation of $\alpha$ and $\varepsilon$ together determine the correlation between domestic and exporting taste parameters. With a choice of $\beta=0.5, \sigma_{\alpha}=2$ and

Table 3 Baseline simulation: chosen parameters and results endogenous variables

\begin{tabular}{lllllr}
\hline Baseline parameters & \multicolumn{5}{c}{ Endogenous variables } \\
\hline Marginal costs & $a$ & 0.5 & Domestic cutoff value & $\alpha^{*}$ & 1.01 \\
Fixed costs & $f$ & 1 & Cutoff to start exporting & $\breve{\alpha}$ & 3.46 \\
Fixed export costs & $f_{x}$ & 1 & Cutoff successful exporting & $\alpha_{x}^{*}$ & 1.69 \\
Sunk entry costs & $f_{e}$ & 10 & Prob. to start exporting & $\operatorname{Pr}($ Exp $)$ & 0.14 \\
Sunk export costs & $f_{e x}$ & 10 & Prob. successful exporting & $\operatorname{Pr}($ Succ $)$ & 0.66 \\
Iceberg trade costs & $\tau$ & 1.2 & Average popularity & $\widetilde{\alpha}_{t}$ & 1.42 \\
Death probability & $\delta$ & 0.025 & Number of domestic firms & $N$ & 17 \\
Substitution elasticity & $\sigma$ & 3.8 & Number of exporting firms & $N_{x}$ & 2 \\
Cultural similarity & $\beta$ & 0.5 & Price index & $P$ & 0.21 \\
Standdev alpha & $\sigma_{\alpha}$ & 2 & Average profit & & 0.41 \\
Standdev epsilon & $\sigma_{\varepsilon}$ & 1 & & & \\
Number of workers & $L$ & 100 & & &
\end{tabular}


$\sigma_{\varepsilon}=1$, the correlation between $\alpha$ and $\alpha_{x}$ can be calculated as, $\operatorname{corr}\left(\alpha, \alpha_{x}\right)=$ $1 / \sqrt{1+\frac{\sigma_{\varepsilon}}{\beta \sigma_{\alpha}}}=\sqrt{2 / 3}$. Finally, the level of sunk export costs affects the cutoff parameter to start exporting and without loss of generality, a baseline value of 5 is chosen.

For $\varepsilon$ the simulations are run with a normal distribution, because it is the most logical distribution for a variable that should have mean zero and range from minus infinity to plus infinity. Using convolution the distribution of $\alpha_{x}$, which consists of the distribution of the sum of $\alpha$ and $\varepsilon$, can be determined. In $\mathrm{R}$ integrals do not converge applying convolution with different distributions for the different variables $\alpha$ and $\varepsilon$ (for example Pareto for $\alpha$ and Normal for $\varepsilon$ ). Therefore, it is assumed that $\alpha$ also has a normal distribution, though truncated from below at zero to rule out negative taste parameter values. This implies though that the simulation results should be treated with caution with respect to robustness to distributional assumptions.

The results of the simulation exercise are displayed in Table 1. Starting from the baseline value, the three different types of trade costs are five times increased by $10 \%$ to address the effect of changes in these variables on the probability of exporting and the probability of success in the export market. A set of robustness checks is performed. The results of the robustness checks are not displayed due to space limitations, but are available upon request. ${ }^{14}$ The robustness checks consist of rerunning the comparative statics exercises varying the parameters $f, f_{x}, f_{e}, f_{e x}, \tau, \delta, \sigma, \beta, \sigma_{\alpha}$ and $\sigma_{\varepsilon}$ one at a time. The results in the main text carry through in the robustness analysis, so the signs of effects of changes in trade costs and $\beta$ stay the same.

\section{References}

Albarran P, Carrasco R, Holl A (2009) Transport infrastructure, sunk costs and firms' export behavior. Universidad Carlos III Madrid, Working Paper 09-22

Albornoz F, Calvo Pardo HF, Corcos G, Ornelas E (2010) Sequential exporting. Mimeo

Baldwin RE (1988) Hysteresis in import prices: the beachhead effect. Am Econ Rev 78(4):773785

Baldwin R, Harrigan J (2007) Zeros, quality and space: trade theory and trade evidence. NBER Working Paper No. 13214

Baldwin RE, Krugman PR (1989) Persistent trade effects of large exchange rate shocks. Q J Econ 104(4):635-654

Bekkers E, Francois JF (2010) Large firms and heterogeneity: the structure of trade and industry under oligopoly. Mimeo University of Linz

Bernard AB, Eaton J, Kortum SS (2003) Plants and productivity in international trade. Am Econ Rev 93:1268-1290

Bernard AB, Bradford Jensen J (2004) Why some firms export. Rev Econ Stat 86(2):561-569

Bernard AB, Redding SJ, Schott PK (2007) Comparative advantage and heterogeneous firms. Rev Econ Stud 74:31-66

\footnotetext{
${ }^{14}$ Also the $\mathrm{R}$ code used to run the simulations is available upon request. Running the robustness checks is time intensive, because of the double integrals in the model.
} 
Besedes T, Prusa TJ (2006) Product differentiation and duration of US import trade. J Int Econ 70:339-358

Crozet M, Koenig P, Rebeyrol V (2007) Exporting to risky markets: a firm-level analysis. Mimeo University of Reims

Dana LP (2006) Handbook of research on international entrepreneurship. Edward Elgar, Cheltenham

Das S, Roberts MJ, Tybout JR (2007) Market entry costs, producer heterogeneity, and export dynamic. Econometrica 75(3):837-873

Eaton J, Eslava M, Kugler M, Tybout J (2007) Export dynamics in Colombia: firm-level evidence. NBER Working Paper No. 13531

Eaton J, Eslava M, Krizan CJ, Kugler M, Tybout J (2008) A search and learning model of export dynamics. Mimeo

Felbermayr G, Toubal F (2006) Cultural proximity and trade. Eur Econ Rev 54(2):279-293

Gould DM (1994) Immigrant links to the home country: empirical implications for U.S. bilateral trade flows. Rev Econ Stat 76:302-316

Guiso L, Sapienza P, Zingales L (2004) Cultural biases in economic exchange. NBER Working Paper No. 11005

Hedlund G, Kverneland A (1985) Are strategies for foreign markets changing? The case of Swedish Investment in Japan. Int Stud Manage Organ 15:41-59

Irarrazabal AA, Opromolla LD (2006) Hysteresis in export markets. Mimeo New York University

Jean S (2002) International trade and firms' heterogeneity under monopolistic competition. Open Econ Rev 13:291-311

Kneller R, Pisu M (2008) Export market entry, sunk costs and firm performance. Final Report for Trade and Investment, Leverhulme Centre for Research on Globalisation and Economic Policy

Medin H (2003) Firms' export decisions-fixed trade costs and the size of the export market. J Int Econ 61:225-241

Melitz MJ (2003) The impact of trade on intra-industry reallocations and aggregate industry productivity. Econometrica 71(6):1695-1725

Millington AI, Bayliss BT (1990) The strategy of internationalization and the success of U.K. transnational manufacturing operations in the European Union'. Manag Int Rev 37:199-222

Nguyen DX (2008) Demand uncertainty: exporting delays and exporting failures. Mimeo University of Copenhagen

Nitsch V (2007) Die another day: duration in German import trade. CESifo Working Paper No 2085

Rauch JE (1999) Networks versus markets in international trade. J Int Econ 48:7-35

Rauch JE, Watson J (2003) Starting small in an unfamiliar environment. Int J Ind Organ 21:10211042

Roberts MJ, Tybout JR (1997) The decision to export in Colombia. Am Econ Rev 87(4):545-565

Stoettinger B, Schlegelmilch BB (1998) Explaining export development through psychic distance: enlightening or elusive. Int Mark Rev 15(5):357-372

Venables AJ (1994) Integration and the export behaviour of firms - trade costs, trade volume and welfare. Weltwirtsch Arch 130:118-132 